\title{
Análisis de la impersonalidad en textos jurídicos. Estudio aproximativo de Carteles y Edictos venezolanos ${ }^{1}$.
}

\author{
Analysis of impersonality in legal texts. \\ Approximate study in venezuelans cartel laws and edicts.
}

\begin{abstract}
Alkys Lamas ${ }^{2}$
Lamas. Alkys. miradas $\mathrm{N}^{\circ} 13$ - 2015. ISSN: 0122 994X Págs 100 - 113

Recepción: Mayo 12 de 2015

Aprobación: Octubre 9 de 2015

Publicación: Diciembre 17 de 2015
\end{abstract}

\section{Resumen}

Uno de los tipos de textos que merecen mayor atención de estudio por las diferentes disciplinas lingüísticas es el texto jurídico. A pesar de la pluralidad característica de esta especialidad de orden legal, los documentos procesales que mayor publicación y circulación poseen (incluso en la prensa impresa o digital) lo conforman los Carteles en sus principales tipos: de Notificación, de Citación, de Emplazamiento, de Remate, o de Intimación, y los Edictos. Esta investigación se propuso indagar en las diferentes manifestaciones con las que dispone la impersonalidad gramatical en la construcción de expresiones procesales y sentenciales. Esas atribuciones pudieran permitir la definición y el desarrollo de temáticas propias de: i) la concepción y la proyección generalizadas de los valores ideológicos planteados en los documentos que son objetos de estudio; y ii) la regulación de los tratamientos permisivos y restrictivos que manifiesta el poder en el ámbito de civil. En este sentido, se pretendió a partir de los niveles morfológico y sintáctico, la identificación y la interpretación de la impersonalidad de tipo semántico sintáctica expresada por la partícula "se", luego las posibles vinculaciones que este nivel puede tener con los niveles léxico y discursivo propios de los textos analizados.

1 Este artículo de investigación lingüística se inscribe en el área de "Morfo - sintaxis" correspondiente con la línea de investigación "El español de Venezuela". Dicha línea es administrada por el Centro de Investigaciones Lingüísticas y Literarias “Dr. Hugo Obregón Muñoz” (CillHom) de la UPEL Maracay.

2 Alkys Lamas es Profesora de Lengua y Literatura (UPEL Maracay - Venezuela, 2006), Magíster en Lingüística (UPEL Maracay - Venezuela, 2011) y actualmente candidata a Doctora en Historia (UCAB Caracas - Venezuela). En el año 2012 obtuvo, por parte de la Academia Venezolana de la Lengua, el Premio Andrés Bello mención Filología Hispánica. Ha centrado sus intereses de investigación en áreas como lexicografía, morfo - sintaxis y análisis del discurso. Actualmente se desempeña como Docente en la categoría Asistente y con dedicación Tiempo Completo en la Universidad Pedagógica Experimental Libertador, núcleo El Mácaro, Aragua - Venezuela. Es además miembro activo desde el año 2011 del Centro de Investigaciones Lingüísticas y Literarias "Dr. Hugo Obregón Muñoz" (CillHom) de la UPEL Maracay - Venezuela. Correo electrónico contacto: alkyslamas@gmail.com 
Palabras Clave: texto jurídico; carteles; edictos; impersonalidad semántico sintáctica; partícula "se".

\section{Abstract}

One type of texts that deserve more attention studied by the different language disciplines is the legal text. Although this feature plurality of specialty legal, procedural documents that have greater publication and circulation (even in printed or digital media) is made Cartel Laws in the main types: Notice, Citation, Siting, Auction, or Summons, and the Edicts. This research aimed to investigate the various demonstrations that have grammatical impersonality in building process and sentential expressions. These powers would allow the definition and development of own issues: i) the design and projection of the generalized ideological values raised in the documents are subjects of study; and ii) the regulation of permissive and restrictive treatment manifesting power in the field of civil. In this sense, it was intended from the morphological and syntactic levels, identification and interpretation of the impersonality of semantic - syntactic expressed by the form "se" possible links then this level may have with the lexical levels and own discursive texts analyzed.

Key Words: legal text; cartel laws; edicts; impersonality semantic - syntactic; form "se".

\section{Introducción}

El estudio de la impersonalidad en la lengua española ha sido estimada por algunos lingüistas como "una de las cuestiones más difíciles, más atractivas y, me atrevería a decir, más apasionantes, de la sintaxis española". (Llorente Maldonado de Guevara, 1971). En efecto, la impersonalidad gramatical contempla la utilización de diversas estrategias de índole tanto sintáctico como pragmático y semántico, condición que le atribuye determinado matiz "heterogéneo" al reconocimiento y descripción sistemáticos de los diversos tipos de impersonalidad manifiestos en una lengua que registra con notoria frecuencia de uso las llamadas "incorrecciones" y/o "agramaticalidades" que reclaman su estudio bien por la vía descriptiva (usual), o bien por la vía normativa.

Si bien lo que comprende el carácter "impersonal" en una oración gramatical apunta a aquello que "carece de sujeto, sea expreso o tácito" (DRAE, 2014), este criterio debe analizarse según dos vertientes disciplinarias de la lingüística, propias para este tipo de oraciones: la impersonalidad semántica en oposición a la impersonalidad sintáctica. En la primera se considera una "oración semánticamente impersonal" aquella que oculta el agente o el actor de la acción verbal debido a una indeterminación, generalización o encubrimiento intencional, lo que insta a darle tratamientos semántico y pragmático a los elementos que la conforman. En la segunda, se entiende como "oración sintácticamente impersonal" aquella que adolece de sujeto léxico - sintáctico lo cual no implica necesariamente la ausencia del "quién" o del "actor" de la acción verbal expresada. De modo que, autores como Gómez Torrego (1994) plantean el necesario discernimiento que todo interesado en el fenómeno de la impersonalidad debe procurar considerar en sus oraciones objetos de estudio: 1) prevalencia de impersonalidad netamente sintáctica;2) prevalencia de impersonalidad netamente semántica; y 3) coactividad de impersonalidad tanto sintáctica como semántica.

Considerando estas nociones preliminares, el caso que ocupa este estudio se centra 
en el análisis de oraciones impersonales sintácticas y semánticas $\mathrm{y}$, en el repertorio de subtipos que se contienen éstas, la aproximación a las impersonales con se empleadas en las estructuras textuales de Carteles y Edictos como recursos pertenecientes al espectro que constituye el discurso jurídico venezolano. Para ello, se propone esta investigación: 1) examinar la impersonalidad sintáctica aplicada en una selección hecha de Carteles y Edictos publicados en prensa de circulación nacional (Venezuela); 2) identificar el uso de oraciones impersonales con la partícula se dentro de los cuerpos de los Carteles y Edictos con el fin de describir sus funciones gramatical, textual y, en los casos que lo ameriten, discursiva; y 3 ) analizar las incidencias de apariciones y usos de las diferentes modalidades que adquieren la impersonalidad sintáctica y la impersonalidad semántica en Carteles y Edictos objetos de estudio.

\section{Marco de referencia}

\section{Mecanismos y funcionalidad de la impersonalidad. Algunas referencias}

La impersonalidad en el español ha sido estudiada por gramáticos notables en su afán por procurar brindar visiones amplias $y$, en lo posible, completas en lo relativo a la descripción, análisis e interpretación de las diversas presentaciones de este "fenómeno" presente tanto en el plano oral como en el plano escrito de la lengua. Andrés Bello (1984) planteó, en su Gramática de la Lengua Castellana, que las oraciones impersonales integran proposiciones irregulares anómalas. El autor apela al carácter activo o neutro de los verbos y su "pase" a la impersonalidad distinguiendo los casos de pasividad refleja y los matices de ambigüedad que pudieran vinculársele a casos de impersonalidad que exigen una necesaria interpretación semántica. Pero en su cometido de exhaustividad, Bello intenta darle completitud a las estructuras de las oraciones impersonales en lo que respecta a sus funciones sintácticas y su explicación en los niveles de uso de la gramática de la lengua castellana. En función de esto, y tiempo después, la Real Academia Española (2011) precisa los criterios teóricos y técnicos que se necesitaban para disolver la ambigüedad que planteaban las interpretaciones de los significados reflexivo, recíproco y de pasiva refleja con especial atención en oraciones que referían a persona. Se insertan y diferencian las nociones: "sujeto no expreso" o "sujeto sobreentendido", "sujeto indeterminado" y, "agente" lo cual permitiría complementar con los análisis sintácticos, los análisis semántico y pragmático.

Algunas otras observaciones teóricas previas a las que se desarrollan en esta investigación, y que constituyen referencias a la definición y a la clasificación particular sobre la impersonalidad gramatical, se tienen aparte de la visión amplísima de Alarcos Llorach (2001), quien sigue las trayectorias definitorias de GiliGaya(1993), se encuentran las brindadas por Francisco Marcos Marín (1972). El autor aporta tipificaciones morfológicas con base en criterios lógicos vinculados a la naturaleza del predicado, en específico, el verbo; sin embargo, dichos criterios son planteados con notorias diferencias respecto a los postulados de la Real Academia Española; esto es debido a las puntualizaciones que Marcos Marín realiza en torno a las varias y distintas formas de manifestación de las oraciones impersonales y su necesaria discriminación.

En otro orden, Llorente Maldonado de Guevara (1971) establece dos grupos de construcciones impersonales: las obligatorias y las opcionales. En lo que refiere a este último grupo, el carácter 
potestativo de la impersonalidad viene determinado por el predicado -que no necesariamente debe poseer carácter impersonal- cuyo verbo debe presentarse siempre en tercera persona del singular, en este sentido, la formulación en tercera persona "es precisamente el exponente del carácter impersonal de estas oraciones, lo que podríamos llamar el «morfema de impersonalidad»."

Preciso este "morfema de impersonalidad", el autor le adjudica laboriosidad para su análisis e interpretación ya que su manifestación y comportamiento en diversas construcciones oracionales exige predeterminar dos características generalizables para lo que refiere la condición impersonal; el autor remite a: "1) Motivación de la expresión de la impersonalidad". Al hacer enlace de estos criterios, tres son las causas que mayor preponderancia poseen para la generación de la expresión impersonal:

$1^{\circ}$ ) Desconocimiento del sujeto. Como no sabemos cuál es el sujeto a que el predicado apunta, no hay más remedio que recurrir a la expresión impersonal $[\ldots]$

$2^{\circ}$ ) Omisión deliberada del sujeto, sujeto que, a diferencias del caso anterior, es perfectamente conocido por el hablante; por discreción, prudencia, táctica, conveniencia, etc., el hablante no quiere hacer referencia al sujeto, y recurre también a la expresión impersonal [...]

$3^{\circ}$ ) Desconocimiento del sujeto por parte de los oyentes o interlocutores; no es oportuno, entonces, que el hablante haga referencia al sujeto, sujeto que para los demás no tiene interés.
Si bien son comprendidas las anteriores indicaciones como causas no-gramaticales coadyuvantes de la impersonalidad gramatical, son reconocidos además diversos procedimientos propios de la lengua española que explicitan el o los elementos gramaticales que, en su conjunción interna, modalizan la impersonalidad. Por su importancia y frecuencia determinante en la práctica lingüística se refieren las siguientes:

1) Segunda persona del singular de la voz o diátesis activa.

2) Segunda persona del plural de la voz o diátesis activa.

3) Primera persona del plural de la voz o diátesis activa.

4) Tercera persona del plural de la voz o diátesis activa.

5) Forma pronominal átona de segunda persona singular más tercera persona del plural de la voz o diátesis activa.

6) Forma pronominal átona de segunda persona del plural más tercera persona del plural de la voz o diátesis activa.

7) Voz o diátesis pasiva en su modalidad analítica o perifrástica.

8) Construcciones con SE.

9) Construcciones con UNO, UNA y tercera persona del singular de la voz o diátesis activa.

10) Construcciones obligativas del tipo Hay que + infinitivo.

En lo que concierne a estos procedimientos, vale comentar que en los tres primeros casos es indudable el carácter impersonal de las frases construidas bajo esos esquemas puesto que apelan al uso de la segunda persona $\left(n^{\circ} 1\right.$ y 2$)$ con lo cual, el carácter subjetivo y afectivo resalta e insta a la implicación de aquel que habla equiparándose con el resto de un colectivo al que se hace pertenecer. Incluso, el tercer 
procedimiento es netamente subjetivo y solidario, así el uso de la primera persona del plural promueve el paralelismo e igualdad de condiciones de todo o todos los referidos. En cuanto al cuarto procedimiento se destaca que, pese al uso de la tercera persona del plural (denotador impersonal), se suma la presentación de un carácter objetivo y neutro lo cual estimula al efecto de "exclusión", "alejamiento" o "distanciamiento" lo que refuerza la impersonalidad de la expresión de aquel que habla: nulidad en "solidaridad" e "inclusión".

A consideración de Llorente Maldonado (ob. cit.), los procedimientos $\mathrm{N}^{\circ} 5$ y 6 constituyen variantes extensivas de los procedimientos $\mathrm{N}^{\circ} 1$ y 2 . No obstante, lo que merece destacarse es que: “... la segunda persona (de singular o plural), aunque vaya representada no por un verbo, sino por un pronombre, y no la tercera persona del plural que aparentemente es el exponente de la impersonalidad.

Uno de los procedimientos que recibirá especial atención lo es el $\mathrm{N}^{\circ} 7$, esto se motiva por la relación que guarda con los textos jurídicos de estudio de esta investigación: los Carteles y los Edictos. El empleo de la voz pasiva perifrástica, con verbo en tercera persona del singular o del plural, se le conoce además como "oración segunda de pasiva" (carente de complemento agente); este tipo de oración -aunque relacionada con la pasiva con se ofrece el beneficio del carácter objetivo y neutro requerido, por ejemplo, en el lenguaje jurídico y administrativo.

En atención a la oración pasiva con se, ésta ofrece importantes soportes procedimentales en lo que refiere a la impersonalidad, entre ellos: 1) el empleo o no de sustantivos o sintagmas nominales; y 2) el uso de estas oraciones en la lengua coloquial, lengua culta y en la literaria. Sin embargo, frente a estas cualidades, es meritorio poner de relieve que el punto de interés de las pasivas con se reside en la interpretación morfosintáctica que se debe hacer de la partícula "se", esto en relación con el grado de exposición que de la impersonalidad puede ofrecer en casos puntuales o, en última instancia, el grado de indiferenciación del sujeto como atributo cercano a la impersonalidad gramatical.

En el penúltimo procedimiento de impersonalidad se emplean los indefinidos UNO, UNA como recurso apelativo ante la presencia de un verbo pronominal, es decir, "reflexivo, ingresivo, de estado, de movimiento, etc., y así evitar la cacofonía $s e-s e$; en este sentido, se asume como remedial" (Llorente Maldonado, ob. cit.) cambiar el primer se, el se impersonal, por el indefinido equivalente Uno, Una, según el que hable sea varón o hembra". Una acotación especial que contemplan para sí el empleo de los indefinidos Uno, Una lo es -aparte del uso corriente con toda diversidad de verbos y, el notorio rasgo subjetivo (afectivo)- la diferenciación de género que suponen Uno (hombre) y Una (mujer) aunque, "es interesante observar que cada vez es más frecuente el uso de Uno cuando el hablante es una mujer; se neutraliza, por lo tanto, la oposición Uno: Una, y Uno se gramaticaliza, adquiriendo un sentido verdaderamente indeterminado aplicable a los dos sexos indiscriminación." (Llorente Maldonado, ob. cit.)

Como último procedimiento puntualizado por Llorente Maldonado (ob. cit.) se dispone de una construcción obligativa utilizada sólo en forma impersonal conjunto con el verbo en tercera persona del singular, es decir, Haber que + infinitivo (Hay que...; Había que...; Habrá que...) Este procedimiento, parte de su carácter objetivo, cuenta como una construcción 
impersonal potestativa ya que es factible para el hablante elegir entre: Hay que...; Tiene que...; Ha de...; Debe...; Debe de...

Si bien esta capitulación clasificatoria elaborada por el referido autor constituye un profuso estudio de la impersonalidad, es pertinente abrir la visión de este fenómeno en Carrasco (1971) quien centra su atención en explorar "sin discriminación" los diversos procedimientos de las predicaciones sin sujeto específico tomando como marco de análisis sus características sintácticas además de particularizar situaciones contrastivas de dichos procedimientos en el plano discursivo, es decir, mediante la noción de subjetividad propuesta por Benvéniste.

Como punto inicial, Carrasco (ob. cit.) hace dos divisiones de las llamadas "construcciones impersonales": A) Predicaciones referentes a procesos naturales que se objetivan como puros acontecimientos y pueden prescindir de la apoyatura de un sujeto, de las cuales "parece que la única condición para este tipo de predicaciones es la presencia de un locativo explícito o implícito", y B) Predicaciones referentes a procesos atribuidos a seres humanos pero que no llevan sujeto específico, dentro de las cuales "figuran las diversas construcciones con $\mathrm{SE}$ indeterminado, la $3^{\circ}$ pers. del plural, la $2^{\circ}$ pers. del sing. y la $3^{\circ}$ pers. sing. con el sujeto uno..."

No obstante, existe un punto de análisis fundamental para la comprensión de la implicación o no de un sujeto -humano por demás- en las oraciones con manifestación de impersonalidad (completa o parcial). En opinión del autor, la forma "se" dispone de una capacidad de neutralización muy inherente a ella, de manera que, es "totalmente indiferente a cada una de las personas y por esta razón puede incluirlas a todas." Esto explicaría cómo ocurre contrariamente con las varias personas gramaticales, por ejemplo, la $3^{\circ}$ pers. del pl. excluye al hablante interlocutor, sin embargo, la $2^{\circ}$ pers. del sing. Incluye a la $1^{\circ}$ y a la $2^{\circ} \mathrm{y}$, aunque no excluye a la $3^{\circ}$ pers., se desentiende de ella; mientras, Uno refiere al hablante aunque bien puede excluir o no tanto a su interlocutor como a terceras personas. Otorgando énfasis Carrasco a su interpretación del predominio -incluso a niveles discursivos- de la forma SE, puntualiza que: 1) a nivel de la lengua, la característica esencial es la indiferenciación máxima; y 2) la misma indeterminación que sirve de materia nocional a SE lo hace apto para tomar en el discurso el puesto de cada uno de los pronombres de la declinación personal, esto explicaría: a) que la cualidad de la "indiferenciación" no se limite a la persona sino que se extienda al número y al género; y b) que la forma SE puede determinarse de alguna manera por un elemento del contexto oracional o, en último caso, por algún factor relativo a la situación extralingüística.

Siendo esto último un atributo definitorio de los diversos compartimientos de la forma SE, aún queda una variante comportamental de la misma que es básica para la indeterminación del sujeto, es decir, para las construcciones impersonales apreciadas como procedimientos alternativos interdependientes al de las predicaciones de persona específica.

Frente a esta interpretación de tipo semántica que permite la impersonalidad gramatical, Gómez Torrego -de quien ya se ha hablado al principio de este artículo-, categoriza, clasifica y reúne en tres grandes grupos a las diversas manifestaciones que encuentra la impersonalidad en el español actual. La aludida clasificación es enumerada y resumida de acuerdo con los planteamientos de impersonalidad propios de los textos jurídicos y/o legales: 
1. Impersonales semánticas

1a) Pasivas reflejas

Llevan la partícula gramaticalizada se.

Disponen de sujeto léxico.

No llevan agente expreso.

\section{1b) Oraciones segundas de pasiva}

Tradicionalmente se llama así a las oraciones pasivas con "ser".

No llevan agente expreso.

Poseen carácter generalizado o indeterminado, no obstante, sí disponen de sujeto sintáctico.

Ha sido incorporado en esta subclasificación el acompañamiento que recibe el verbo "ser" de un verbo en participio, de modo que, sobre el primero recaería la función de "verbo base" mientras que sobre el segundo, la función de verbo auxiliar lo cual de alguna manera hace que califiquen o adjudiquen atributo al sujeto sintáctico que les antecede a ambos.

1c) [Perífrasis verbal: Haber + Participio // Ser / Estar + Participio]. En lo que concierne a la función y uso de las perífrasis en el ámbito de la impersonalidad.

\section{Impersonales sintácticas y semánticas}

\section{2a) Impersonalidad con se}

Llevan una marca de impersonalidad: se.

Su sujeto sintáctico es cero.

Se sugiere un "agente" o "actor", que o bien es arreferencial o bien está generalizado.

Los tipos de impersonalidad sintáctica con se son:

Verbo intransitivo.

Verbo copulativo con atributo de sujeto cero.

Verbo transitivo y complemento directo con $a$.

3. Impersonales

exclusivamente

sintácticas

3a) Impersonalidad con DAR

"Dar por"
Se consideran construcciones impersonales sintácticas porque es imposible la presencia o recuperación de un sujeto léxico sintáctico.

Ha sido añadida una observación inherente al lenguaje jurídico que vincula la expresión impersonal "dar por" con la partícula "se" (darse por + participio). Esta estructura matiza -con cierta gradación- a la impersonalidad de reflexividad.

Expresiones cuya frecuencia de uso se ubican en el lenguaje coloquial (aunque en esta investigación se evidenciará su uso).

\section{La impersonalidad gramatical en textos jurídicos}

\section{Caracterización estructural global del texto jurídico}

El lenguaje jurídico es considerado un "lenguaje especial"; este calificativo apunta a las causas que motivan: a) la especificidad; b) la espacialidad, y c) la especialidad que por demás enmarcan a lenguaje y hombre en el tiempo. Evidentemente, son las ciencias puras y las ciencias políticas dos de las más representativas actividades intelectuales que definen, regulan y potencian el ejercicio de la racionalidad en múltiples actividades individuales y colectivas que bien tiene a desempeñar el hombre cotidianamente. Toda necesidad e intencionalidad de actuación sobre la realidad, llevadas por las sendas del control y la organización, implican para la lengua el diseño y práctica de lenguajes diversificados y acordes con las eventualidades que ofrecen, en específico, el acatamiento de leyes y ordenaciones civiles.

Ríos (2005) expone que el derecho como disciplina de articulación social, fija la organización política de la sociedad por tanto, ha supuesto que su diversificación 
-y a su vez especificidad- conformen un "tecnolecto" capaz de ejercer en el Derecho y la Administración del Estado acciones que:

\section{...institucionalizan jurídica}

y políticamente la sociedad, definiendo el lugar de los individuos y de los grupos en su seno, así como las relaciones entre unos $\mathrm{y}$ otros. El lenguaje emanado de esa institucionalización ocupa un lugar central en el horizonte de todos los hablantes, tratándose, por ende, de un lenguaje que establece normas y que prescribe comportamientos. En este sentido, hablamos de un lenguaje que tiende, de un lado a la impersonalidad y la generalización, pues se refiere al conjunto social $\mathrm{y}$, de otro, a la exhaustividad en cuanto previsión de toda la complejidad que las relaciones sociales y políticas comportan.

Espatrónlógicoentonces, laimpersonalidad y la generalización en el lenguaje jurídico por las relaciones referenciales que hace éste con el campo ideológico al cual se vincula (valores, delitos, compromisos, responsabilidades) y, mucho más obligante para su regulación: los dilemas que acarrean las relaciones del hombre con el poder. Ahora bien, es pertinente definir en una primera aproximación, las principales características que ofrece el lenguaje jurídico en lo concerniente al léxico y la gramática. Ríos (ibíd) así los puntualiza:

Lenguaje específico, pues, por su modo de significar, lo es también por sus características léxicas y, en menor medida, gramaticales. Entre las primeras sobresalen los tecnicismos $y, \quad$ ocasionalmente, algún arcaísmo. Gramaticalmente pueden citarse los siguientes rasgos: abundantes perífrasis; abundancia de complementación y subordinación; gran cantidad de gerundios y formas no personales del verbo, enumeraciones; oraciones impersonales y de pasiva refleja; desplazamiento de la $1^{\mathrm{a}}$ y $2^{\mathrm{a}}$ persona a la $3^{\text {a }}$; futuro de obligatoriedad; uso del futuro de subjuntivo, recurso a definiciones, al estilo aforístico, a las citas y referencias legales.

\section{Metodología}

\section{Corpus de estudio}

Para realizar esta investigación fueron seleccionados diez (10) Carteles y diez (10) Edictos publicados en el diario de circulación nacional "El Nacional" durante el lapso de tiempo de cuatro semanas distribuidas entre el 14 de enero de 2008 y el 14 de febrero de 2008, ubicados (en la mayoría de los casos) en el cuerpo cultural "Escenas" (sección Publicidad) y el resto, o minoría de los casos, en el cuerpo social "Ciudadanos" (sección Publicidad). Se acota que en lo que concierne a los Carteles fueron recabadas en sus diferentes denominaciones las siguientes cantidades:
a) Carteles de Citación: 04 .
b) Carteles de Notificación: 02 .
c) Carteles de Emplazamiento: 02.
d) Carteles de Intimación: 02.

Vale indicar que la intención inicial de la investigación (en particular, la recolección de los Carteles), consistió en tomar dos muestras de cada "sub - tipo": Citación; Notificación; Emplazamiento; Intimación, y Remate. Sin embargo, estos últimos suelen no circular con frecuencia en la prensa nacional y/o regional, caso aparte lo es la adjudicación de la publicación del embargo y venta pública de bienes muebles e inmuebles en Carteles de Notificación, no obstante en la presente investigación no se contempla este caso. Se acota que, 
el número de Carteles de Citación captados (04) obedece a la preponderancia de este tipo en prensa; otro caso de particular dominio de escena corresponde a los Carteles de Notificación. Estas dos últimas tipologías acaparan la atención de casos considerablemente concurridos en la sociedad como lo son: Demandas por Despidos Ilegales entre otros.

En lo que concierne a los Edictos, predominan tres temas del total de diez (10) seleccionados:

a) Citación de herederos (conocidos o no) con motivo de Partición de Bienes Muebles e Inmuebles: 03.

b) Citación de herederos (conocidos o no) con motivo de Desalojo: 02.

c) Citación de herederos (conocidos o no) con motivo de Resolución de Contrato e Indemnización de Daños Morales: 02.

\section{Instrumentos de Recolección y Análisis de Datos}

Un punto neural de la recolección de muestras lo constituye la distribución, segmentación, cuantificación y jerarquización de los datos que se pretenden captar y vincular con la teoría de la impersonalidad gramatical contemplada en párrafos anteriores. Para lograr ello, fue diseñado un modelo de Matriz de Segmentación y Agrupación de datos. Las variables de análisis que contienen dichas matrices (aplicables tanto para los Carteles como para los Edictos) encuentran su basamento en la clasificación que, de la impersonalidad gramatical en la lengua española, hace Gómez Torrego (ob. cit.) Las categorías que rigen la metodología son las indicadas:

\begin{tabular}{|c|c|c|}
\hline \multirow{2}{*}{\multicolumn{3}{|c|}{$\begin{array}{c}\text { IMPERSONALIDAD SINTÁCTICA Y SEMÁNTICA } \\
\text { IMPERSONALIDAD CON "SE" }\end{array}$}} \\
\hline & & \\
\hline $\begin{array}{l}\text { VERBO } \\
\text { INTRA. }\end{array}$ & $\begin{array}{c}\text { VERB. } \\
\text { COP. } \\
\text { ATR. } \\
\text { SUJ. C. }\end{array}$ & VERB. TRANS., + C.D. CON \\
\hline \multicolumn{3}{|c|}{ IMPERSONALIDAD SEMÁNTICA } \\
\hline $\begin{array}{l}\text { ORAC. SEG. } \\
\text { DE PASIV. }\end{array}$ & $\begin{array}{r}\text { PASIVA } \\
\text { REFLEJA }\end{array}$ & PERIF. VERBAL \\
\hline $\begin{array}{l}\text { (ser + } \\
\text { Partic.) }\end{array}$ & (se reflex.) & Haber + Part. ser/estar + P. \\
\hline \multicolumn{2}{|c|}{$\begin{array}{l}\text { IMPERSONALIDAD } \\
\text { SINTÁCTICA }\end{array}$} & $\begin{array}{l}\text { OTROS CASOS: NO } \\
\text { IMPERSONALIDAD }\end{array}$ \\
\hline \multicolumn{2}{|c|}{$\begin{array}{l}\text { IMPERSONALIDAD } \\
\text { CON "DAR" }\end{array}$} & PASIVA CON “SE” \\
\hline
\end{tabular}

Cuadro 1.Impersonalidad. Categorías de clasificación

Estas categorías fueron seleccionadas de la amplia clasificación que hace Gómez Torrego en cuanto a la impersonalidad sintáctica y/o semántica. Sin embargo, debido a la observación previa y registro de observaciones, pudo constatarse que son estos los casos que con mayor frecuencia de aparición y uso ofrecen los textos de Carteles y Edictos. Un punto que conviene aclarar lo es la disposición de la categoría "Otros casos: no impersonales. Pasivas con «se», ya que (aunque en un reducido número), fueron registrados casos de este tipo en algunos textos examinados lo cual configura una situación que si bien, conviene incluir por su uso, también, por su mismo uso frente a casos genuinos de impersonalidad con la partícula «se», conviene identificar y discernir el uno del otro.

Mediante la segmentación (hecha en algunos casos a través del criterio de enunciado y, en otros, a través del criterio de oración), se procedió a vaciar en casillas de clasificación por categorías de impersonalidad a fin de recabar los varios sub - totales derivados de cada uno de los Carteles y Edictos analizados hasta medir la frecuencia de aparición de casos. 
Es indispensable explicitar el criterio de segmentación de las muestras; ello se debe a la redacción y estructuración por párrafos (en algunos casos la ausencia de estos, es decir, por el uso del párrafo único o en bloque), que determina la presentación y estilo textual y discursivo de la disciplina jurídico - administrativa de base: el Derecho Civil ${ }^{1}$.

El total decasos (segmentaciones) obtenidos de los varios Carteles recolectados ofrecen los siguientes resultados:

\begin{tabular}{|c|l|c|}
\hline CARTEL N & TIPO DE CARTEL & $\begin{array}{c}\text { N'DE } \\
\text { CASOS }\end{array}$ \\
\hline 1 & Notificación & 04 \\
\hline 2 & Notificación & 05 \\
\hline 3 & Citación & 04 \\
\hline 4 & Citación & 04 \\
\hline 5 & Citación & 03 \\
\hline 6 & Citación & 03 \\
\hline 7 & Emplazamiento & 03 \\
\hline 8 & Emplazamiento & 02 \\
\hline 9 & Intimación & 09 \\
\hline 10 & Intimación & 10 \\
\hline & & 47 \\
\hline
\end{tabular}

Cuadro 2. Corpus de estudio. Carteles: tipificación y casos reportados

El total de casos (segmentaciones) obtenidos de los varios Edictos recolectados ofrecen los siguientes resultados:

\begin{tabular}{|c|l|c|}
\hline EDICTO & & N$^{\mathbf{0}} \mathbf{D E}$ \\
& TEMÁTICA EDICTO & \\
\hline $\mathbf{N}^{\mathbf{0}}$ & & CASOS \\
\hline 1 & Notificación & 03 \\
\hline 2 & Notificación & 02 \\
\hline 3 & Citación & 03 \\
\hline 4 & Citación & 03 \\
\hline 5 & Citación & 03 \\
\hline 6 & Citación & 05 \\
\hline 7 & Emplazamiento & 05 \\
\hline 8 & Emplazamiento & 06 \\
\hline 9 & Intimación & 04 \\
\hline 10 & Intimación & 06 \\
\hline & & 40 \\
\hline
\end{tabular}

Cuadro 3. Corpus de estudio. Edictos: tipificación y casos reportados

Luego, la aparición de casos de impersonalidad gramatical registrados se tipifica y agrupa según los cánones de clasificación previamente mencionados. La representación gráfica de estos casos objetos de estudio se efectúa mediante histogramas que registran las frecuencias relativas y las absolutas correspondientes a Carteles y Edictos.

\section{Discusión de resultados}

La aparición y enumeración de las características presentes en cada uno de los niveles de análisis propuestos inicialmente (gramatical: aspectos morfosintácticos; textual: aspectos inherentes a la estructura y a la organización de las temáticas así como de los patrones léxicos distintivos; y discursivo: aspectos relativos al estilo del discurso jurídico y de la praxis jurídica como tal), merecen la coordinación de los mismos en función de apreciar que el uso que se hace de cada uno de los Carteles y de los Edictos configura a su vez el uso de otros elementos lingüísticos reunidos en un único texto. Cabe entonces listar las observaciones más puntuales y recurrentes apreciadas en las muestras de estudio antes referidas.

1. Predominio de la Frase Nominal sobre la Verbal. Esta primera apreciación muestra la alta frecuencia de uso de sustantivos postverbales derivados en "-ción", “-ión”, “-al”, "-able", y “-ado", cuyas funciones estriban en la designación precisa de los elementos judiciales que se emplazan tanto por la autoridad (Juez con sustento en el cuerpo de leyes) como por los emplazados (solicitante [s] y solicitado [s]). Los sustantivos postverbales con mayor amplitud de uso son: "disposición", "notificación", "articulación", "prescripción", fijación", "publicación", “consignación”, “citación”, "publicación”. 
2. Reforzamiento de la abstracción nominativa. La abstracción inherente de los sustantivos empleados en Carteles y Edictos favorece la exposición objetiva de los valores y/o intereses de poder contenidos en las leyes. En este sentido, el carácter abstracto contribuye con el manejo "estandarizado" y equitativo para las partes interventoras en las situaciones de conflicto planteadas en los textos objetos de estudio, observación que promueve además a mencionar la condición minoritaria de los verbos (presentados en forma personal) en los mismos: "expediente", "cánones", "arrendamiento", "inmueble", "ley", "código", "cartel", "avocamiento", "acción", "condición", "legítimo", "indemnización", "paternidad", "daño", "moral", "posesión", "desplazamiento", "expropiación", "nulidad", “orden", “civil", entre otros.

3. Supresión de la alternatividad (o redundancia) semántica mediante precisión nominativa. Apoyada en la conjunción de participios como por ejemplo: "Firmada y sellada" o "Dada y sellada", así como la conjunción de sustantivos abstractos acompañantes del membrete institucional o firma del Juez a cargo del caso legal, por ejemplo: "Dios y Federación".

4. Concurrencia de verbos en infinitivo. El infinitivo, como una de las formas no personales del verbo, contribuye a la impersonalidad gramatical. En el caso de los textos jurídicos, Carteles y Edictos muestran agrupaciones de verbos en infinitivo lo cual refuerza el tono de notificación, sentencia y advertencia: "Se hace saber a, "deberá comparecer", "de no comparecer", "deben comparecer", "deberá ser publicado". Es de hacer notar la frecuente inclusión del verbo principal "deber" en anteposición del verbo en infinitivo hasta constituir construcciones perifrásticas.

5. Escasez de conectores a consecuencia del uso predominante de Formas no Personales del Verbo. Es así como el participio y el infinitivo conforman nexo sin requerir el soporte de otro nexo como tal.

6. Predominio de Estructuras Oracionales Impersonales con la partícula "se"

a. En Carteles. Los resultados derivados de las matrices indicaron que, dentro de las variantes de presentación que poseen las oraciones impersonales con "se", son las de Verbo Intransitivo las que alcanzaron mayor frecuencia de empleo en Carteles de diferentes especies (Notificación, Citación, Emplazamiento, Intimación). Es así como, de un total de 49 oraciones impersonales con "se", 34 correspondieron a las de verbo intransitivo lo que representa aproximadamente un $69,38 \%$ de frecuencia absoluta.

Luego de estas, le siguieron las oraciones de Verbo Transitivo y Complemento Directo con "a", las cuales reunieron un parcial de 15 oraciones de las 49 totales lo que representa aproximadamente un $30,61 \%$ de frecuencia absoluta. 
Se acota que, en lo que refiere a las oraciones de Verbo Copulativo con Atributo de Sujeto Cero, no se logró acumular frecuencia alguna siendo en consecuencia la cifra 0 su total alcanzado.

b. En Edictos. Los resultados arrojados por las matrices indicaron que, dentro de las variantes de presentación que poseen las oraciones impersonales con "se", son las de Verbo Intransitivo las que alcanzaron mayor frecuencia de empleo en los Edictos estudiados. En este sentido, se registraron de un total de 47 oraciones impersonales con "se" distribuidas en diez (10) modelos de Edictos, un parcial de 32 apariciones determinó su predominio, lo que representa aproximadamente un $68,08 \%$ de frecuencia absoluta.

Seguidas de estas, se ubican las oraciones de Verbo Transitivo y Complemento Directo con "a", registrando un parcial de 15 apariciones lo cual representa aproximadamente un $31,91 \%$ de frecuencia absoluta.

Se acota que, en lo que refiere a las oraciones de Verbo Copulativo con Atributo de Sujeto Cero, no se logró acumular frecuencia alguna siendo en consecuencia la cifra 0 su total alcanzado.

Este análisis también mostró el empleo en estructuras sentenciadoras del pronombre átono "se" en posición postverbal, en este sentido, se potencia el efecto de objetividad y distanciamiento del lector hacia el texto a la par que procura magnificar el rol que ejercen las autoridades judiciales en las figuras el Juez del Tribunal y abogados participantes, limitando o minimizando mediante orientación imperativa, la o las figuras interpeladas. Por ejemplo: "advertir" ("adviértase"), "librar" ("líbrese"), "haber" ("haberse"), "intimar" ("intímese"), "dar" (“darse por”), “entender" (“entenderse”), "publicar" ("publíquese"), "notificar" ("notifíquese"), entre otros.

De igual manera debe hacerse observación del uso del "se" como pasivizador. Respecto a ello, se registraron dos (02) casos de uso de oraciones pasivas con "se". Un caso corresponde con el Cartel $\mathrm{N}^{\mathrm{o}} 1$ : “... las cuales [consignaciones de cánones de arrendamiento] se encuentran a la orden y disposición de su Representada." Mientras, el segundo caso corresponde al Edicto $\mathrm{N}^{\mathrm{o}}$ 7: "Una línea casi recta desde el punto marcado con Letra (C), Coordenadas 7180E-9690 en una longitud de Ciento cincuenta metros (150 mts.) con terrenos del Señor GIUSEPPE RUSSO FERRANTE, cuyo Punto (D) se encuentra ploteado en la Cota $1140 ; \ldots]$

Al dar continuidad con el uso del "se", vale agregar el respaldo que, con amplia frecuencia posee el dativo "le": con ello enfatiza el carácter acusatorio recibido por el imputado como objeto temático del texto jurídico. Por ejemplo: "se le hace de conformidad con...", "se le advierte que...", "se le designará...", "se le hace saber...", "se les conceden...", "se le nombrará...", entre otros. Incluso este mismo "se" puede encontrarse con el mismo valor y la misma función aún en forma enclítica, por ejemplo: "advirtiéndosele que..."

7. Co - ocurrencia de impersonalidad semántica. Lo particular que presentan estos casos es que, mientras en las impersonales con "se" no era factible recuperar ni el sujeto sintáctico ni al agente de la acción ('impersonalidad sintáctica y semántica'), en esta categoría no es posible recuperar al agente aunque sí al sujeto; sin embargo puede que, con este basamento, la impersonalidad 
semántico - sintáctica haya encontrado en los textos jurídicos el asidero donde esparcir sus frecuencias de apariciones.

En lo relativo a las cifras obtenidas, se tiene que las perífrasis verbales conformadas con la estructura [Haber + Participio] o [Ser/Estar + Participio] obtuvieron los siguientes resultados:

a. $\quad$ En Carteles. De un total de 12 oraciones clasificadas en la categoría "Impersonalidad Semántica", 11 se ubican en el tipo "Perífrasis Verbales", cifra que engloba a los diez (10) Carteles estudiados y que representa aproximadamente el $91,66 \%$ de frecuencias absolutas para el uso del "se" reflexivo.

Se acota que, las Oraciones Segundas de Pasiva conformadas por la estructura [ser + Participio] no obtuvo ningún registro de uso en las muestras examinadas, a lo cual le corresponde la cifra 0 en frecuencia absoluta.

b. En Edictos. De un total de 13 oraciones clasificadas en la categoría "Impersonalidad Semántica", 8 se ubican en el tipo "Pasiva Refleja", cifra que engloba a los diez (10) Edictos estudiados y que, de alguna manera, se contrapone a lo registrado en los Carteles. No obstante estas 8 oraciones de Pasiva Refleja representan aproximadamente el $61,53 \%$ de frecuencias absolutas. En complemento a este registro, se tiene que las "Perífrasis Verbales" concentran 5 apariciones en el total de Edictos examinados lo que representa (aproximadamente) un $38,46 \%$ de frecuencia absoluta.

8. Empleo del verbo "dar" como manifestación de la impersonalidad sintáctica. Los casos registrados de "Impersonalidad Sintáctica" en los Carteles y Edictos seleccionados constituyen casos particulares por la estructura que estos presentan ["dar" + "se" + "por" + Participio], en ese sentido, han sido asumidas este tipo de oraciones como manifestaciones de esta categoría de impersonalidad, obteniéndose de un total de diez (10) Carteles estudiados: 7 oraciones tipificadas. En lo relativo a los Edictos, de un total de diez (10) examinados se registraron 5 oraciones coincidentes con la estructura aludida.

\section{Conclusiones}

El estudio realizado desde la noción de la impersonalidad gramatical, bajo diferentes enfoques teóricos (aunque no disímiles o distantes entre sí) permitió la observación de este fenómeno en algunos de los textos jurídicos producidos dentro de su cotidianidad administrativa en Venezuela. Esta indagación a través de Carteles y Edictos coadyuva en la puntualización de las siguientes consideraciones:

1. En el ámbito semántico, el eje temático más trabajado en Carteles y Edictos es el de las potestades inquisitoriales.

2. En el ámbito pragmático, los tonos personales que construyen los grados de formalidad de los textos estriban en las estrategias generadoras de distanciamiento y la dicotomía autoritativo - subordinativa.

3. En el ámbito gramatical, los Carteles y Edictos estudiados se caracterizan por presentar elementos morfológicos y sintácticos promotores de procedimientos particulares de este tipo de textos tales como:

a. Construcción de oraciones impersonales dentro de las cuales se constata el predominio de la impersonalidad semántico - sintáctica a través de oraciones estructuradas con la partícula "se". 
b. Predominio del empleo de la perífrasis verbal $[$ Haber + Participio/Ser o Estar + Participio] para la manifestación de la impersonalidad semántica. Sin embargo, conviene apuntar la discrepancia de este criterio (propio de los Carteles analizados) respecto con el predominio de la pasiva refleja [se reflexivo] en los Edictos. Una observación lingüística que merece profundización aparte.

c. Alta frecuencia de sustantivos abstractos, en contribución a la designación objetiva, neutral y equitativa de elementos situacionales tomados de una realidad particular objetada (léxico modelador).

d. Importancia y atención concedida al desplazamiento de la primera y segunda persona del singular y plural a la tercera persona del singular y, en casos menores, a la tercera persona del plural.

4. Por último, en lo que concierne al estilo discursivo de los textos estudiados vale destacar que, como textos escritos y formales, el tecnicismo y apropiación de claves pragmáticas permite confirmar la ausencia de marcas dialectales o variables cronolectales, sexolectales o etnolectales lo que profiere, en determinada gradación, un matiz "críptico" que remite a la máxima formalidad demandadas por autoridades administradoras de la justicia: las leyes, el Juez y los abogados tribunalistas.

\section{Referencia Bibliográfica}

Alarcos Llorach, E. (2001). Gramática de la Lengua Española. Madrid: Espasa Calpe. Tercera reimpresión.

Bello, A. (1984) Gramática de la Lengua Castellana para Uso de los Americanos. Madrid: EDAF.

Carrasco, F. (agosto de 1977). "Sobre la impersonalidad en español: hacia una sistematización de los enunciados de persona no específica". En: Actas del $6^{\circ}$ Congreso Internacional de Hispanistas, Universidad de Toronto. [Versión digital] Consulta: 2015, abril 19, http://cvc.cervantes.es/obref/aih/pdf/06/ aih.pdf

Gili Gaya, S. (1993). Curso Superior de Sintaxis Española. Barcelona: Bibliograf.

Gómez Torrego, L. (1994). La impersonalidad gramatical: descripción y norma. Madrid: Arco Libros.

Llorente Maldonado de Guevara, A. (1971). "La expresión de la impersonalidad en español". En: AIH. Actas IV. Centro Virtual Cervantes. [Versión digital] Consulta: 2015, marzo 19, http://cvc.cervantes.es/obref/aih/ pdf/04/aih_04_2_019.pdf

Marcos Marín, F. (1972). Aproximación a la gramática española. Madrid: Cincel - Kapelusz.

Real Academia Española. Asociación de Academias de la Lengua Española (2011). Nueva gramática de la lengua española. Manual. Bogotá: Planeta Colombiana.

Real Academia Española. Asociación de Academias de la Lengua Española (2014). Diccionario de la Lengua Española. $23^{\circ}$ edición. [Versión digital] Consulta: 2015, junio 01 , http://dle.rae.es/

Ríos, J. T. (2005). "Las sentencias judiciales: estudio y análisis sociolingüístico". En: Revista Electrónica de Estudios Filológicos, 9 [Versión digital] Consulta: 2015, marzo 19, http://www.um.es/tonosdigital/znum9/ corpora/juridicos.htm

\section{Notas al lector}

1 Para una mayor y mejor comprensión de los lineamientos que condicionan la administración de las ciencias jurídicas en Venezuela (y con atención en las potestades civiles) se sugiere consultar el Código de Procedimiento Civil de fecha 18 de septiembre de 1990, publicado en Gaceta Extraordinaria del Congreso de la República de Venezuela, 4209 (Extraordinario). 